\title{
O retrato da cultura nas páginas do Jornal do Tocantins: análise da editoria Magazine
}

\author{
William Castro Morais ${ }^{1}$ \\ Edna de Mello Silva²
}

\section{Resumo}

Este artigo analisa a editoria Magazine, do Jornal do Tocantins, como espaço para divulgação do jornalismo cultural e das manifestações artísticas da cidade de Palmas. Para desenvolvê-lo, foram investigados os temas e a abrangência territorial, por meio de categorias para análise de conteúdo proposta por Laurence Bardin (2011), como caminho metodológico. O corpus compreende as publicações nos meses de março, abril e maio de 2017, que reuniu o total de 78 edições. Os resultados apontaram maior número de notícias de caráter local, com informações ligadas à agenda cultural, notas de eventos, exposições, colunismo social, além de seções de cinema, novelas, horóscopo e shows. Os conteúdos são compostos por entretenimento e sem nenhuma reflexão artística.

Palavras-chaves: Cultura. Jornalismo Cultural. Tocantins.

\section{Abstract}

This article analyzes the editorial of Magazine, of the Jornal do Tocantins, as a space for the dissemination of cultural journalism and the artistic manifestations of the city of Palmas. To develop it, the themes and the territorial scope were investigated, through categories for content analysis proposed by Laurence Bardin (2011), as a methodological path. The corpus comprises the publications in the months of March, April and May of 2017, that gathered the total of 78 editions. The results showed a greater number of local news items, with information related to the cultural agenda, event notes, exhibitions, social columnism, as well as cinema

\footnotetext{
1 Mestre em Comunicação e Sociedade, pela Universidade Federal do Tocantins. Possui MBA em Marketing e Recursos Humanos e Especialização em Assessoria de Comunicação Empresarial e Institucional. Graduado em Comunicação Social - Jornalismo. Membro do Grupo de Pesquisa Jornalismo, Mídia e Memória (JOIMP-UFMA). Email: jorwilliamcastro@gmail.com.

2 Mestra e doutora em Ciências da Comunicação pela ECA-USP. Pós-doutorado com pesquisa sobre história do telejornalismo pela UFRJ (2015). Atualmente é vicecoordenadora do Curso Superior de Tecnologia em Design Educacional da Universidade Federal de São Paulo (UNIFESP). É docente colaboradora do PPGCOM/UFT. É coordenadora do GP de Telejornalismo da Intercom. É vice-líder do Grupo de Pesquisa Jornalismo e Multimídia (CNPq/UFT). Email: prof.ednamello@gmail.com.

Revista Pauta Geral-Estudos em Jornalismo, Ponta Grossa v.5, n.2, p.181-198, Jul/Dez 2018.
} 
sections, novels, horoscopes and shows. The contents are composed of entertainment and without any artistic reflection.

Keywords: Culture. Cultural Journalism. Tocantins.

\section{Introdução}

As características históricas de um povo e seu território, bem como a trajetória que envolve a economia, política, sociedade e a ideologia podem estar ligados à cultura, sua regionalização e a forma de ver o mundo e as comunidades ao redor. Nessa perspectiva, a cultura também está associada à capacidade de projetar comportamentos e representar uma identidade, por meio de manifestações que distinguem os indivíduos. O conceito de cultura é discutido em várias definições e assume um caráter global, em que são incluídas as mais diversas manifestações da arte e o compartilhamento de práticas sociais. Dessa forma, a cultura em sua abordagem no jornalismo, pode estar ligada às representações de classes, cotidiano, entre outras questões, por isso este estudo parte do entendimento de que o jornalismo cultural integra as esferas do processo comunicacional em espaços voltados para a divulgação do universo artístico. Para Gadini (2008), ao desenvolver esse setor jornalístico, é possível contemplar diferentes olhares em torno das estratégias editoriais na tematização dos conteúdos publicados.

Esta pesquisa, recorte da dissertação "A tematização da cultura em diários regionais: análise do Jornal do Tocantins e o Estado do Maranhão", vinculada ao Programa de Pós-Graduação em Comunicação e Sociedade - PPGCOM, da Universidade Federal do Tocantins - UFT, lança um olhar sobre a informação jornalística cultural na capital Palmas, com objetivo de analisar o espaço voltado para a cultura, observando as características que demonstram a percepção da área publicada nos referidos impressos, a partir de suas particularidades e aspectos regionais.

Para o presente artigo, é apresentada análise que envolve os assuntos relacionados à cultura publicados na editoria Magazine, do Jornal do Tocantins (JTO), e engloba saúde, qualidade de vida e alimentação, moda, colunismo social, programas de televisão, entre outros, seguindo padrão da matriz da empresa em Goiânia ${ }^{3}$. Para compreender a abordagem da cultura e abrangência territorial das publicações, foram

3 O Grupo Jaime Câmara é formado por 24 veículos de comunicação, sediados nos Estados de Goiás e Tocantins, além do Distrito Federal. Na capital Goiânia, o jornal O Popular também possui a editoria Magazine.

Revista Pauta Geral-Estudos em Jornalismo, Ponta Grossa v.5, n.2, p.181-198, Jul/Dez 2018. 
analisados, em uma abordagem quantitativa, os dados referentes aos meses de março, abril e maio de 2017, totalizando 78 edições do jornal.

Apesar do tema cultura no jornalismo impresso já existir no país há anos, com diversas pesquisas, o trabalho se justifica pelo seu caráter local e devido aos poucos estudos registrados no âmbito do jornalismo cultural no Tocantins, contribui para produção acadêmica. $O$ impresso foi escolhido por ser o mais antigo diário em circulação da capital tocantinense e por sua relevância histórica.

\section{Cultura: conceitos e reflexões}

Do verbo latim colere a palavra cultura, em meados do século XVIII, passou do conceito de cultivo da terra para o de "cultura do espírito humano" em meio a várias discussões. Conforme Williams (2011), são muitas concepções sobre o termo, pois coexiste, muitas vezes representações dos campos antropológico e sociológico para indicar o modo de vida de um grupo ou de uma sociedade como um todo. As transformações históricas, industriais, democráticas e sociais também modificaram a palavra cultura, que muitas vezes representava um sentimento de hostilidade e constrangimento. Para o autor, o significado de cultura perpassa definições multidisciplinares. O termo tem sua simbologia no desenvolvimento das faculdades humanas e a partir disso, as obras artísticas e as práticas começam a representar a própria cultura, que assume um caráter universal e engloba diversas manifestações, sem estabelecer valor ou hierarquias uma sob as outras.

O desenvolvimento da palavra cultura é um registro de um número de reações importantes e permanentes a essas mudanças em nossa vida social, econômica e política, e pode ser visto, ele mesmo, como um tipo especial de mapa por meio do qual a natureza das mudanças pode ser explorada (WILLIAMS, 2011, pág. 18-19).

Do ponto de vista antropológico, a primeira definição de cultura foi formulada por Edward Tylor, na sua obra Primitive Culture (1871), em que buscou demonstrar que cultura é um fenômeno natural que possui causas e regularidades, o que permite proporcionar a elaboração de leis sobre o processo cultural e a evolução. Logo, a cultura é "aquele todo complexo que inclui conhecimento, crença, arte, moral, lei, costume e quaisquer outras capacidades e hábitos adquiridos pelo homem" (TYLOR, 2009, p.69). 
Tylor observou os fatos relacionados à cultura a partir de uma ótica geral e sistemática, além de estudar a cultura nas mais diversas sociedades e com um olhar sob vários aspectos, seja na perspectiva material, de simbologia e corporal.

Com isso, a cultura e a civilização formam um conjunto bastante complexo que engloba o conhecimento, as crenças, a moral, a arte, as práticas sociais e hábitos assimilados pelo homem como agente ativo na sociedade. Nesse contexto, conforme White (2009), cultura e homem são inseparáveis, um não vive sem o outro. Logo, a cultura tem uma simbologia para o homem, em que cada sociedade tem a sua definição e o termo tem seus significados distintos. Ela não é homogênea, é variável com o tempo e muda de lugar para lugar, pois o significado de uma coisa depende de sua análise, contexto, hábitos ou modo de vida.

Para Kellner (2001), a cultura representa uma participação em que as pessoas criam sociedades e identidades, pois ela modela os indivíduos na sua essência e na capacidade de ver o mundo. A cultura passa então a dominar a vida cotidiana, como o lazer, as opiniões e comportamento social, fornecendo subsídios para se analisar quem tem ou não poder.

É importante o público conhecer os fundamentos da indústria cultural para resistir a certas dominações e significados impulsionados pela mídia. O rádio, a televisão, o cinema e os outros produtos da indústria cultural fornecem os modelos daquilo que significa ser homem ou mulher, bem-sucedido ou fracassado, poderoso ou impotente (KELLNER, 2001, pág. 9).

Desta maneira, a mídia e a informação moldam a visão que desejarem para vender a imagem na sociedade. De acordo com Kellner (2001), há uma cultura veiculada pela mídia com imagens, sons e espetáculos que se aproximam do dia a dia das pessoas, dominando seu tempo e contribuindo para modelar a vida, que resulta em uma identidade forçada. Essa cultura da mídia busca cada vez mais público e audiência para atrair lucro, por meio dos produtos que são mercadorias, e assim os indivíduos se conformam com a organização da sociedade. Esse empobrecimento dos produtos culturais, a forma como a diversão e o entretenimento são disponibilizados tornam-se dispositivos utilizados para negar a arte como instrumento de reflexão e dificultam o homem ser crítico e autônomo.

\section{Jornalismo cultural}

Revista Pauta Geral-Estudos em Jornalismo, Ponta Grossa v.5, n.2, p.181-198, Jul/Dez 2018. 
Em 1711, a revista The Spectator, lançada por Richard Steele (1672-1729) e Joseph Addison (1672-1719), inicia a trajetória do jornalismo cultural juntamente com a história da cidade de Londres e era voltada a figura do homem urbano, com abordagens sobre livros, óperas, costumes, teatro, festivais de música, entre outros assuntos. Um homem bastante "preocupado com modas, de olho nas novidades para o corpo e a mente, exaltado diante das mudanças no comportamento e na política" (PIZA, 2008, p.12). Era um momento em que o jornalismo abria as portas para valorização das artes e das ideias, com base nas transformações econômicas e sociais proporcionadas após o Renascimento na Europa.

Segundo Piza (2008), a revista The Rambler tinha conteúdo publicado por Samuel Johnson (1709-1784), também conhecido como dr. Johnson, sendo considerado o primeiro grande crítico cultural da humanidade. Em meados do século $\mathrm{XX}$ o jornalismo cultural no Brasil é representado por análises de obras literárias importantes, bem como se transformou em um espaço para escritores mais críticos. No jornal Diário de São Paulo, o poeta Mário de Andrade fez carreira ao escrever sobre música e literatura, além de pincelar alguma informação que destacasse as artes visuais e as crônicas da cidade, sempre em primeira pessoa e com abordagens na vida artística.

De acordo com Piza (2008), após Machado de Assis e José Veríssimo, os jornais e revistas brasileiras passaram a ter mais espaço ao crítico profissional e informativo, que além de analisar obras importantes, também refletia sobre a cena literária e cultural vigente na época. Em 1928 surgiu a revista O Cruzeiro, uma das mais importantes do Brasil nos anos 30 e 40, com linguagem acessível, reportagens investigativas, artigos, contos, humor e ilustrações. Com o passar dos anos as práticas jornalísticas foram mudando significativamente e ainda estão em processo de inovações diante das tecnologias que surgem a todo instante. Segundo Rêgo (2013), no começo do século XX, a divulgação de informações da cultura artística ganhou força com as revistas ilustradas que deram atenção especial para esse tipo de jornalismo. Além da evolução nos meios de comunicação, o uso dessa temática foi sendo aperfeiçoada e o jornalismo cultural se potencializou no segmento do entretenimento e da vida social dos artistas.

Segundo Piza (2003), nos anos 30, os suplementos culturais deram um salto, com a crescente industrialização e novidades que possibilitaram o aumento da produção dos jornais, como as máquinas rotativas, o papel-bobina e a composição mecanizada de texto. Com o maquinário mais moderno, foi inserido o uso de fotografias e as Revista Pauta Geral-Estudos em Jornalismo, Ponta Grossa v.5, n.2, p.181-198, Jul/Dez 2018. 
propagandas ganharam destaque nas páginas de veículos como o Jornal do Commercio, Gazeta de Notícias e O Estado de S. Paulo. Em 1950, o jornal Correio da Manhã cria um caderno cultural dominical chamado O Quarto Caderno. Esse período impulsionou o jornalismo cultural brasileiro. Em 1956, surgiu o Suplemento Literário, do jornal O Estado de S. Paulo, com a presença de importantes intelectuais e escritores para atrair o interesse do leitor para as artes, marcando uma renovação no espaço da cultura nos impressos do país. Em 1960, a revista Diners foi criada, repleta de reportagens interpretativas, literatura e críticas, e também surgiu $O$ Pasquim, tabloide semanal que tinha política, humor e cultura.

Apenas nos anos 1980, os grandes jornais O Estado de São Paulo e a Folha de São Paulo, estabeleceram seus espaços culturais diários, o Caderno 2 e a llustrada, respectivamente. De acordo com Gadini (2003), o surgimento da maioria dos cadernos culturais foi devido ao fortalecimento da indústria cultural, poder aquisitivo, além do crescimento populacional. Para Romancini e Lago (2007) os impressos seguiram um padrão que modificou a forma de fazer jornalismo.

Parte-se do princípio que o leitor, de modo geral, tem menos tempo para a leitura. Daí, para atender melhor este consumidor, a proliferação das colunas de notas, textos e parágrafos curtos, recomendações no sentido do uso de uma linguagem acessível, concisa e didática, o que acarreta certa padronização. (ROMANCINI; LAGO, 2007, p.180).

Piza (2008), destaca que nos anos 90, além das mudanças estruturais nos jornais, a década é caracterizada pela liberdade de imprensa, modernização tecnológica, e inserção de temas ligados à moda, design e gastronomia.

Para Gadini (2008), são diversas percepções em torno da produção, circulação e consumo da cultura pelo jornalismo e, que pode contribuir para uma formação profissional mais solidificada na área. Segundo o autor, as relações sociais são influenciadas pelo modo como são as cidades, os bairros ou as comunidades se desenvolvem. Logo, as feiras livres, bares, cafés, esquinas de bate-papo, dentre outros locais, também podem se tornar referências de diálogo e ação cultural, sendo utilizados como ferramentas que identifiquem os elementos para participarem da rotina produtiva dos jornais e se tornarem notícia. Conforme Assis (2008), os jornais atuais não destacam um fato e não fazem discussões em torno dele. O que se vê são espaços destinados de forma quase exclusiva para conteúdos de entretenimento e que não promovem nenhum senso reflexivo do leitor. Revista Pauta Geral-Estudos em Jornalismo, Ponta Grossa v.5, n.2, p.181-198, Jul/Dez 2018. 
Seria impossível negar que o trabalho desenvolvido por veículos de cultura deixou de ser o que era no início de sua história. É mais do que latente que, hoje, a produção de "serviço" é muito maior do que de conteúdos interpretativos, críticos e questionadores. E mesmo aqueles que conseguem se manter mais para o lado da reflexão, o faz num espaço tímido, com destaque para fotografias, artes gráficas e outros elementos "decorativos" (ASSIS, 2008, p. 185).

Desta forma os espaços voltados para a divulgação cultural são reservados para atender interesses comerciais, o que dificulta uma posição mais crítica do público consumidor das informações. Uma das principais características do jornalismo cultural, atualmente, é o trabalho de divulgação feito pelos jornalistas da área, que tem como missão fazer a mediação entre a arte e o público, incluindo com antecedência as novidades sobre os produtos culturais, que costumam ser os lançamentos de filmes e livros, estreias de peças, novelas e outros, segundo Franthiesco Ballerini (2015). Os assuntos abordados no jornalismo cultural se revelam com temáticas mais leves e descontraídas, que carregam informação e entretenimento, mas não causam necessariamente uma reflexão sobre o conteúdo divulgado. O jornalismo começou a ganhar novas formas e os conteúdos foram sendo preenchidos por outros assuntos. Com esse novo olhar para as pautas se observam questões que abordam tendências, revelam novidades, apresentam dicas e roteiros diversos, destacam personagens e assim o entretenimento ganha espaço nos veículos de comunicação ao oferecer aos leitores.

\section{A comunicação regional e o jornalismo local}

As transformações do jornalismo passam por contextos históricos, frutos da organização da sociedade, que envolvem questões geográficas de espaço, território, lugar e região, em que são colocados em diferentes papéis dentro da comunicação. Com isso, os registros são feitos para contemplar comunidades distintas, com a divulgação dos acontecimentos de cada localidade.

Para Oliveira (2013), o exercício da comunicação regional no dia a dia é de coletar, tratar e publicar informações jornalísticas, publicitárias, de entretenimento, entre outras, para atender às necessidades dos públicos e aos indivíduos e grupos de interesse, principalmente político e econômico. Para ele, a mídia regional procura pensar os lugares e espaços onde originam cada cultura e, assim, se manifestar, a partir de suas identidades, características e demandas. 
Sousa (2004) afirma a imprensa veicula informações sobre a região e as pessoas que nela habitam com base em assuntos veiculados pela opinião pública local, fortalecendo a prática jornalística, que tem as funções de informar, formar e entreter. Consequentemente, com a comunicação regional, a população fica mais próxima dos acontecimentos e têm acesso às informações sobre o território em que vive, participando de forma direta ou indiretamente dos temas abordados e ampliando os espaços para discussão de seus interesses.

O conceito de mídia regional é utilizado de forma genérica por muitos estudiosos, para explicar a mídia que não possui características suficientes para alcançar um patamar considerado de abrangência nacional e, assim, são vistas como "pequena imprensa" e subdividas para dar suporte como "local", "comunitário" "do interior", de acordo com Pinto (2015). Ela apresenta duas perspectivas: uma assimétrica, que condiciona a mídia regional como um grupo homogêneo e sem diferenças, em relação àquelas observadas pela mídia nacional, e a outra com abordagem superlocal, que coloca a mídia regional de maneira particular e individual em cada cidade, estado ou região, incluindo estudos sobre jornalismo nessas localidades. Mas, na avaliação de Pinto (2015), os dois modos ainda não são suficientes para acompanhar o movimento da mídia regional existente nos diferentes estados brasileiros, pois as particularidades de cada local devem ser respeitadas e servem como base para novas pesquisas. A partir desses conceitos, é importante mencionar que as informações são exploradas de acordo com a estratégia editorial dos veículos de comunicação, e assim, a mídia, seja local ou regional giram em torno de benefícios pessoais e empresariais, sem priorizar, em muitas ocasiões, os princípios éticos e de responsabilidade social para a divulgação das notícias para a comunidade.

Com base em Peruzzo (2006), entende-se que o "jornalismo local" reflete o cotidiano, atende e valoriza a demanda local, trazendo os fatos de forma mais instantânea dos acontecimentos de uma determinada sociedade. Nesse sentido, a mídia se ocupa de assuntos mais gerais, que mostram temas sobre as vias públicas, tragédias, problemas e violência, política, serviços públicos, tráfico de drogas, culinária, entre outros, e apresentam as dimensões de proximidade e familiaridade.

Por que ocorre esse novo interesse pelo local? Justamente pela percepção de que as pessoas também se interessam pelo que está mais próximo ou pelo que mais diretamente afeta as suas vidas e não apenas 
pelos grandes temas da política, da economia e assim por diante. Elas curtem as benesses trazidas pela globalização, mas não vivem só do global, que em última instância é uma abstração. Elas buscam suas raízes e demonstram interesse em valorizar as "coisas" da comunidade, o patrimônio histórico cultural local e querem saber dos acontecimentos que ocorrem ao seu redor. (PERUZZO, 2006, p. 5).

Logo, a autora aponta que a mídia local tem a comunicação produzida em informação de proximidade, por isso, essa delimitação territorial caracteriza as mídias locais e regionais. Nessa perspectiva, Camponez (2012) afirma que a proximidade é vista como item estratégico para a seleção dos critérios noticiosos e, também, como um produto mercadológico, para alcançar a fidelização dos diferentes públicos. Então, a proximidade não apresenta somente essa dimensão de território, relacionada ao espaço geográfico, e sim à identidade, história e cultura de um grupo social. Para Camponez (2012, p. 36) a proximidade também está relacionada ao campo psicológico, com "as dimensões temporais, psicoafetivas, socioprofissionais e socioculturais", envolvendo, de alguma forma, o dia a dia e os sentimentos das pessoas. E esses são aspectos que se aliam à representação da mídia regional e sua atuação.

\section{Roteiro de pesquisas do Tocantins}

Foram analisados os registros presentes na Biblioteca Digital Brasileira de Teses e Dissertações (BDTD) e no repositório da Universidade Federal do Tocantins, com algumas palavras específicas para facilitar a busca, como jornalismo cultural, cultura tocantinense, diários regionais e cultura no Tocantins. O caminho foi norteador para conhecer e observar a existência de pesquisas sobre jornalismo cultural, que envolveram os diários impressos locais. Percebeu-se que não houve nenhuma investigação sobre o tema específico no estado nessas duas plataformas. O que se tem sobre a área cultural reflete as manifestações da cultura em algumas cidades históricas, estudos de identidades e características de tradições religiosas. A dissertação de Ana Carolina dos Anjos, defendida em 2015, pelo programa de mestrado em Ciências do Meio Ambiente da UFT, é intitulada "Do girassol ao capim dourado: a apropriação de elementos da natureza na construção de símbolos político-identitários no Estado do Tocantins". O estudo apontou o processo de construção da cidade de Palmas e a invenção de sua identidade cultural oficial, entre os anos de 2003 a 2011 , baseada pela política estadual. 
Do mesmo programa, a dissertação "História, memória e religiosidade na festa do Divino Espírito Santo em Natividade - TO", de Poliana Macedo de Sousa, descreve a organização e os preparativos da comunidade para a festa do Divino Espírito Santo, no município de Natividade. Esse estudo, que se transformou em um livro, fez um resgate histórico das comemorações em Portugal e sua expansão pelo continente europeu e colônias portuguesas, repassadas até hoje a cada geração.

A tese "Religiosidade e devoção: As festas do divino e do rosário em Monte do Carmo e em Natividade - TO" de Noeci Carvalho Messias, do doutorado em História, da Universidade Federal de Goiás, Goiânia, defendia em 2010, apresenta características de algumas manifestações religiosas do estado. Em sua pesquisa, ela destaca a dissertação intitulada "A apropriação de uma tradição: um estudo sobre o festival de música folclórica de Santa Rosa do Tocantins / TO", de Eliane Castro de Souza, da Pontifícia Universidade Católica de Goiás-PUC/GO; além de alguns trabalhos do Campus Universitário de Porto Nacional (UNITINS/UFT), a nível de pós-graduação, como "A festa do Divino Espírito Santo na cidade de Porto Nacional - TO", de Altina Ferreira dos Santos (2002), "O povoado Canela e os impactos culturais após a relocação para o Plano Diretor de Palmas - ARNE 64(508 Norte), de Antônio Miranda dos Santos (2006), entre outras, com abordagem voltada aos aspectos musicais e religiosos dos municípios tocantinenses.

Em 2013, do programa de pós-graduação em Comunicação, Cidadania e Cultura, da Universidade Federal de Goiás, a dissertação de Wendy Almeida de Araújo, analisou "Os ritmos tradicionais nos tambores do Tocantins: constituições identitárias e processos culturais". O tema se apropriou de um projeto de música percussiva que reúne sússia, catira, tambor, congo e roda, ritmos que são referência nas manifestações culturais do Estado.

"As festas da cidade de Porto Nacional - TO: um olhar dos ativistas culturais", de Thalyta de Cássia da Silva Feitosa, do programa de pós-graduação em Geografia, de 2017, traz algumas reflexões sobre o município histórico, com fortes traços religiosos e celebrações cívicas e profanas, que evidenciam o âmbito cultural da comunidade. Com esses dados, observa-se que as pesquisas no Tocantins norteiam temas que discutem, principalmente, as tradições religiosas e manifestações musicais e de danças da cultura de alguns municípios, entre outras abordagens.

\section{Caminho metodológico}

Revista Pauta Geral-Estudos em Jornalismo, Ponta Grossa v.5, n.2, p.181-198, Jul/Dez 2018. 
Para o desenvolvimento desta pesquisa foi adotado o método de análise de conteúdo, com base em Bardin (2011), a partir do levantamento quantitativo do material cultural jornalístico e tratamento dos dados da coleta para análise. Por isso, foi construído um modelo com uso de categorias, em que foram criadas unidades de registro para compreender a tipologia identificada no jornal, que serviu para investigar os temas divulgados e abrangência territorial. Para compreender os espaços de cultura que permeiam a editoria Magazine, o corpus foi composto pelas edições correspondentes a três meses do Jornal do Tocantins, do dia $1^{\circ}$ de março a 31 de maio de 2017. Isso porque de acordo com Gadini (2008, p. 10), "a escolha de um determinado período (mês, semana, dias ou horário, dependendo do produto/serviço) pode influenciar diretamente na caracterização do estudo". Assim, para a pesquisa, o recorte iniciou em datas que não possuem destaques de eventos festivos, presentes no calendário cultural nas capitais, e segue com a aproximação de agendamento midiático com a realização de eventos tradicionais que marcam cada lugar.

Com o propósito de identificar os principais temas ligados à cultura veiculados no jornal, com a análise de conteúdo (AC), foram apontadas categorias com base nas palavras ou frases do texto que se repetem, o que resultou nas expressões culturais que as representam. Os espaços específicos destinados à cultura foram observados, com exceção de colunas ou espaços de serviços fixos e que permanecem sem alterações ao longo do período avaliado, como resumo de novelas, horóscopo, e programação de televisão e cinema, assim como os suplementos com circulação somente aos finais de semana não fizeram parte do estudo. Para análise de conteúdo foram utilizadas as seguintes categorias:

a) Tema

Para compreender de que cultura está se pretendendo falar foram criados os temas de música, teatro e dança, artes visuais, literatura, cinema, patrimônios históricos, manifestações culturais, televisão, colunismo social, esportes, comportamento /moda ou entretenimento/ agenda cultural, religião e outros tipos. Com a abordagem foi possível analisar a composição dos espaços de cultura e a divulgação de determinados assuntos.

b) Abrangência

A produção das notícias segue uma delimitação territorial que se relaciona com a proximidade dos fatos com a comunidade, pois, geralmente, os veículos buscam informação sobre assuntos que fazem parte do cotidiano dos leitores. Para compreender Revista Pauta Geral-Estudos em Jornalismo, Ponta Grossa v.5, n.2, p.181-198, Jul/Dez 2018. 
a abrangência dessas temáticas, foram criadas as categorias local, regional, estadual, nacional e internacional. Nessa distribuição foi levada em consideração a origem da publicação quanto à localidade a que se refere e seus personagens. Essa classificação é importante pela relação que o jornalismo tem com os públicos específicos de cada localidade a partir da percepção do jornal quanto à publicação divulgada.

\section{O Jornal do Tocantins}

Fundado em 18 de maio de 1979, na cidade de Araguaína, em formato tabloide como uma produção da Organização Jaime Câmara, o Jornal do Tocantins teve suas primeiras edições quinzenais. No ano seguinte, o JTO era distribuído gratuitamente em órgãos públicos, mas, devido às mudanças na política de editorial, o periódico começou a ser comercializado por meio de assinaturas, em bancas de revistas, e passou a circular semanalmente. Somente em 1991, os leitores passaram a ter acesso ao jornal duas vezes por semana, e em 1998, a equipe que produzia o jornal foi transferida para a capital do estado, Palmas, o que possibilitou produzir o jornal para ser distribuído de terça a domingo. Nessa época, o JTO era editado em Palmas e impresso em Goiânia, o que causava certas dificuldades para a edição e circulação. Por isso, em 2002, o jornal passou a ser impresso na capital tocantinense e, em 2005, o Parque Gráfico da Organização Jaime Câmara, em Palmas, foi responsável pela impressão.

Atualmente, é o maior jornal impresso do estado, em páginas, tiragem e edições, com circulação de terça a domingo. É composto pelas editorias de Política, Economia e Mundo incluídas no tema Notícias, enquanto segurança pública, transporte, saúde, educação, meio ambiente e urbanismo fazem parte do tema Vida Urbana. Com a última mudança no projeto gráfico em agosto de 2016, o espaço relacionado à cultura e comportamento foi o que mais sofreu alterações, conhecido como Arte \& Vida, passou a se chamar Magazine (conforme figura 1), que engloba mais temas como saúde, qualidade de vida, comportamento, gastronomia, turismo, saúde, bem-estar, seguindo padrão da matriz em Goiânia. Nesse novo formato, os espaços da cultura são divididos em três páginas, com uma reportagem especial na capa e, na parte interna, com textos e notas diversas, a presença da coluna social BIP, além da seção Horizonte, que retrata a vida da sociedade palmense em aniversários, casamentos, viagens, formaturas, inauguração de empreendimentos e demais assuntos. Há também a página voltada para o horóscopo, resumo de novelas, passatempo, charge, quadrinhos e a coluna Crônicas e Causos Revista Pauta Geral-Estudos em Jornalismo, Ponta Grossa v.5, n.2, p.181-198, Jul/Dez 2018. 
(veiculada somente na terça-feira, quando a editoria excepcionalmente tem quatro páginas). Também presente a coluna Lazer e CIA, com roteiros e agenda cultural, responsável pela divulgação de eventos em notas curtas com programação de shows e festas na cidade e região.

Figura 1 - Primeira capa da editoria Magazine

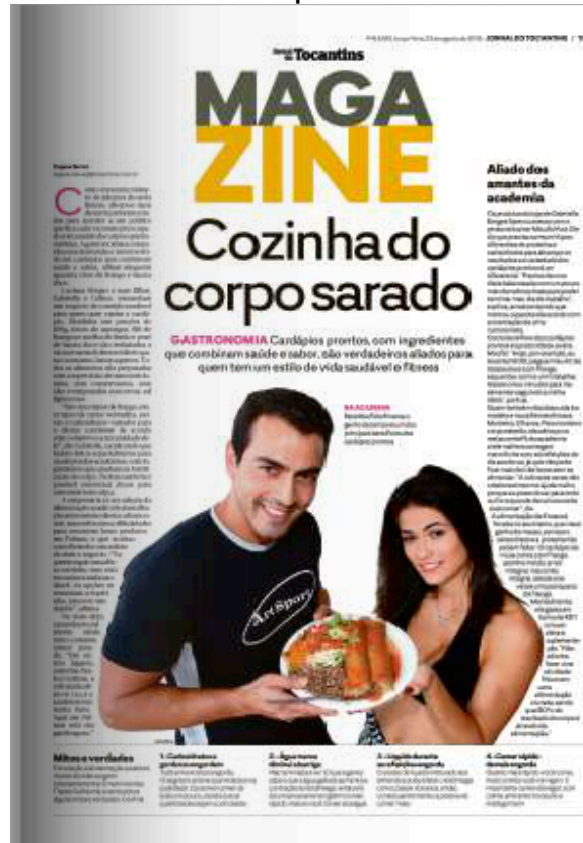

Fonte: Jornal do Tocantins (2016)

Para compreender sobre quais assuntos o jornal tematiza nesse espaço, a pesquisa categorizou os temas que abrangem vários aspectos culturais e abordagens relacionadas, com 577 ocorrências analisadas. Os destaques foram 74 sobre música $(12,8 \%)$, com exemplos de títulos como "Capital da Fé reúne multidão" (edição de 02/03/2017), "Tocantins Sertanejo" (edição de 03/03/2017), "Festival de Metal reúne bandas regionais" (edição de 08/04/2017), "Fundação Cultural apresenta espetáculos musicais e eruditos" (edição de 25/04/2017), "Semana da Cultura em Porto Nacional" (edição 16/05/2017), entre outros. Em seguida, 44 sobre teatro e dança $(7,6 \%) ; 34$ literatura $(5,9 \%)$ e 38 artes visuais $(6,6 \%)$, com divulgação de espetáculos, festivais, exposições de obras, cursos, oficinas, eventos, apresentações no interior do estado e mostras, conforme gráfico a seguir. 
Gráfico 1 - Temáticas das informações relacionados à editoria de cultura

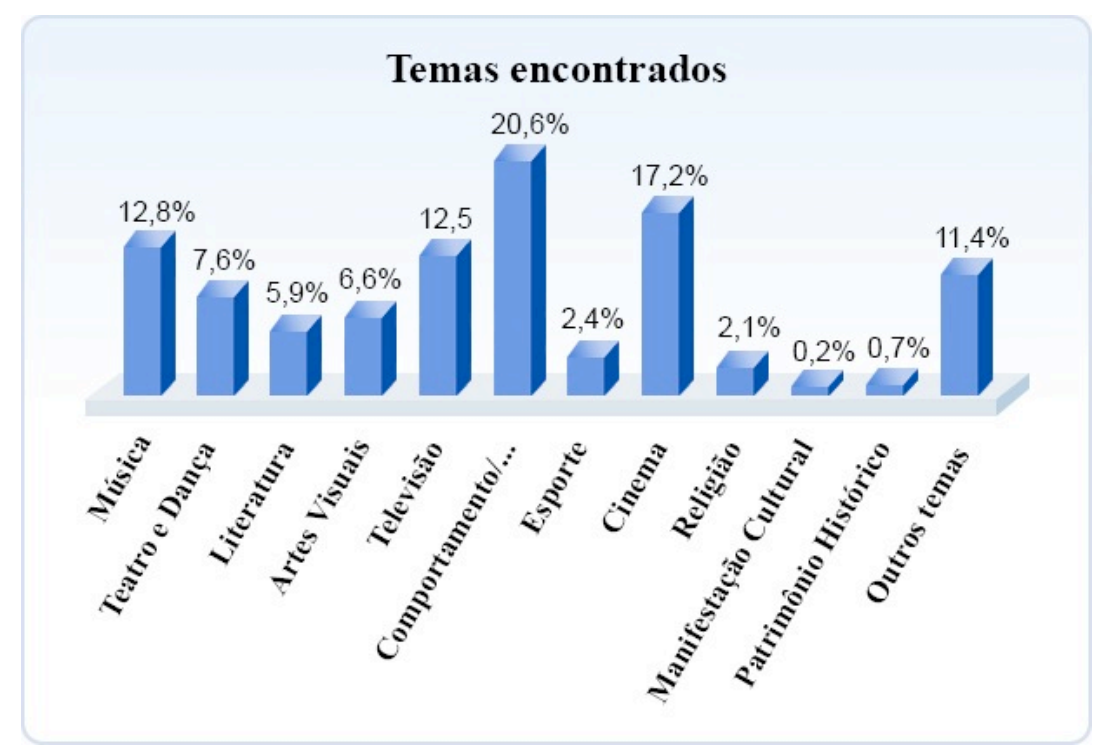

Fonte: Os autores (2018)

Além disso, foram 72 registros de televisão (12,5\%), com detalhes sobre a vida de celebridades, novelas e programas; 99 cinema $(17,2 \%)$, sobre estreia de filmes, bastidores da telona e exibição de documentários; e 12 religião $(2,1 \%)$. Na coleta de dados, tem a ocorrência de uma reportagem que se relaciona com uma manifestação cultural $(0,2 \%)$. Na editoria, também houve quatro informações sobre patrimônio histórico $(0,7 \%)$, com exemplos em "Edital premia ações de proteção aos bens culturais" (edição de 23/05/2017) e "Casa de Patrimônio" (edição de 11/03/2017), com a reforma da Casa Abrigo João XXIII, em Porto Nacional. Outros 66 temas $(11,4 \%)$ foram mapeados e abordaram assuntos sobre meio ambiente, tecnologia, agronegócio, turismo e mundo animal.

Para compreender a abrangência das informações divulgadas e identificar de onde está se falando, foram relacionadas 275 categorias local (48\%); 83 regional (14\%); 41 estadual (7\%), 161 nacional (28\%) e 17 internacional (3\%). Esses dados revelam que a produção cultural tem expressividade, com divulgação de informações locais referentes à cidade de Palmas. De acordo com o gráfico 2, o levantamento apresentou que as ocorrências nacionais superam a regional, estadual e internacional, provavelmente pela publicação de materiais enviados por assessorias ou agências de notícias. 
Gráfico 2 - Abrangência do conteúdo a partir dos textos divulgados

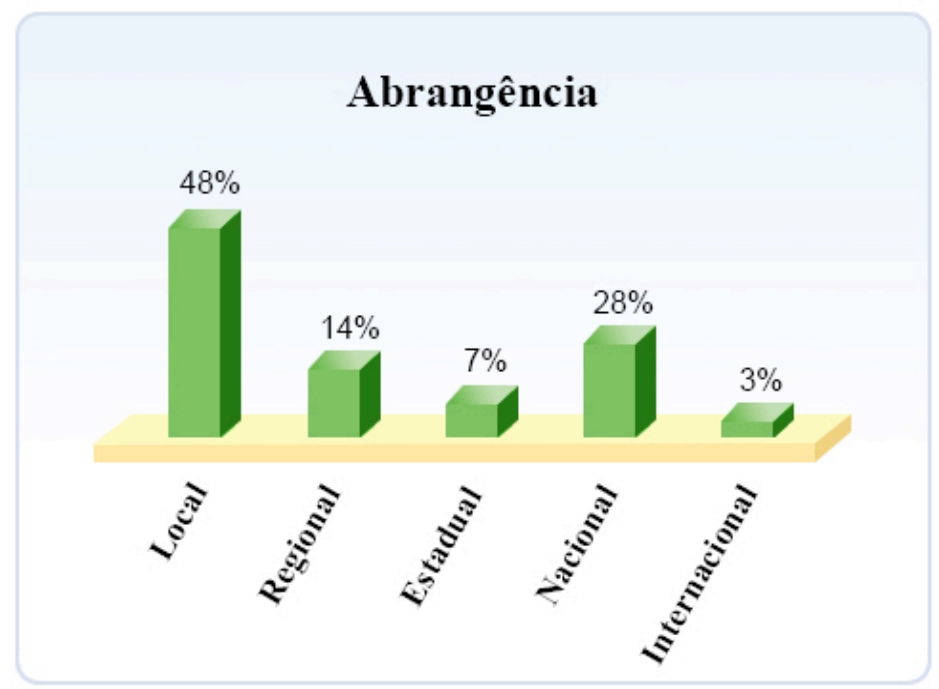

Fonte: Os autores (2018)

Foram observados textos de fontes da Folha Press, Globo Imprensa, Globo e Agência Estado. As reportagens abordam assuntos do cotidiano, como exemplo "Afinal o que é ser saudável?" (edição de 04/03/2017), "Do quarto para o escritório: terapia sexual" (edição de 05/03/2017), "Novo mundo e o Brasil Imperial" (edição de 10/03/2017), "Incentivadores de leitura" (edição de 11/03/2017), "Vivendo um sonho nas passarelas" (01/04/2017), "Arte circense em Taquaruçu" (edição de 05/04/2017), "Exposição exibe obras da artista Graça Arnús" (edição de 04/05/2017), entre outros. Na primeira página, os temas são compostos principalmente, por textos que retratam comportamento, dicas de beleza, moda, roteiros de viagens, culinária, estreia de filmes e novelas. A coluna Crônicas e Causos, veiculada apenas na terça-feira, é escrita por diversos profissionais, tendo rotatividade a cada edição. Foram diagnosticados textos de advogados, escritores, jornalistas, administradores, e retratam no espaço textos sobre a infância, lembranças familiares e variados aspectos da vida urbana.

\section{Considerações finais}

No presente trabalho, com a análise do Jornal do Tocantins, observou-se que as publicações se resumem principalmente às notas de eventos, exposições, programação para o fim de semana, colunismo social e agenda cultural, além de seções de entretenimento e diversão. Não há presença de crítica de filme, peça teatral ou outro Revista Pauta Geral-Estudos em Jornalismo, Ponta Grossa v.5, n.2, p.181-198, Jul/Dez 2018. 
produto de arte, para incentivar o leitor a refletir sobre os conteúdos publicados. Os dados revelaram que no impresso não houve registro de um embate de ideias, com poucas ocorrências da divulgação de valores culturais, que demonstrassem processos de construção de uma identidade cultural ou representações da cidade ou do estado. O que se constata com isso é que os temas abordados possuem pouca abordagem de notícias que destacam temáticas mais amplas sobre a arte.

Dentre os temas investigados, predominou-se o cinema, música, televisão, artes visuais, teatro, dança, literatura e religião. As publicações abordaram sobre espetáculos, festivais, exposições de obras, cursos, oficinas, eventos, apresentações no interior do estado e mostras, além de abordagens sobre meio ambiente, tecnologia, agronegócio, turismo e mundo animal. As referências de abrangência mostraram que a produção cultural local possuem bastante expressividade, com informações referentes à cidade de Palmas, e que as ocorrências nacionais superaram a regional, estadual e internacional. Esse dado pode ser explicado pelo material enviado por assessorias ou agências de notícias da capital.

Nessa perspectiva, apesar das suas peculiaridades, a cultura é vista como um mero utensílio de consumo com a divulgação de shows, colunas sociais e assuntos sem significativa importância cultural para reflexão, senso crítico, resenhas e poucos registros de matérias especiais sobre o universo artístico dos estados. Por isso, acredita-se que esses impressos não fogem da crise do jornalismo cultural e que o usa como jornalismo de serviço, recheado de agenda, textos curtos, notas e pouco espaço para as artes. A compreensão sobre os aspectos culturais, no impresso analisado, reforça a memória coletiva de cada lugar, principalmente na capital onde está sediado. Pelos dados apresentados, percebe-se que a editoria, principalmente na capa e última página, apresentam número menor de veiculações sobre cultura. As informações privilegiam uma parcela de leitores que consome as colunas sociais e demonstra ser um espaço da minoria, por ser elitizado e específico para uma camada da sociedade. Logo, o estudo abre possibilidades para novos olhares sobre a prática do jornalismo cultural do Tocantins, além de despertar o interesse para pesquisa sobre a força do entretenimento.

\section{Referências}

ASSIS, Francisco. Jornalismo Cultural Brasileiro: aspectos e tendências. Rev. Estud. Comun., Curitiba, v. 9, n. 20, p. 183-192, set./dez. 2008 
BALLERINI, Franthiesco. Jornalismo cultural no século 21: literatura, artes visuais, teatro, cinema e música: a história, as novas plataformas, o ensino e as tendências na prática. São Paulo, Summus: 2015.

BARDIN, Laurence. Análise de conteúdo. São Paulo: Edições 70, 2011.

CAMPONEZ, Carlos. Jornalismo regional: proximidade e distanciações. Linhas de reflexão sobre uma ética da proximidade no jornalismo. In: CORREIA, João Carlos. Ágora Jornalismo de Proximidade: Limites, Desafios e Oportunidades. Portugal, Covilhã, UBI, LabCom, Livros LabCom, 2012.

GADINI, Sérgio Luiz. A cultura como notícia no jornalismo brasileiro. Rio de Janeiro: Prefeitura da Cidade do Rio de Janeiro, 2003.

Sérgio Luiz. Breves sugestões e estratégias (metodológicas e contextuais) para compreender os processos editoriais no campo cultural. In: VI Encontro Nacional de Pesquisadores em Jornalismo. Universidade Metodista de São Paulo, novembro de 2008. Anais...110 Sbpjor, p. 1- 14.

KELLNER, Douglas. A cultura da mídia. Bauru, SP: Edusc, 2001.

OLIVEIRA, Roberto Reis de. Espaço, território, região: Pistas para um debate sobre comunicação regional. Space, territory, region: Lanes for a discussion on regional communication. Revista Ciberlegenda, p. 108 - 118. 2013.

PINTO, Pâmela Araújo. Mídia regional brasileira: características dos subsistemas midiáticos das regiões Norte e Sul / Pâmela Araújo Pinto. - 2015. 336 f. Tese (Doutorado em Comunicação) - Universidade Federal Fluminense, Instituto de Arte e Comunicação Social, 2015.

PIZA, Daniel. Jornalismo Cultural. São Paulo: Contexto, 2003.

Daniel. Jornalismo cultural. 3.ed. São Paulo: Contexto, 2008.

PERUZZO, C. Mídia local e suas interfaces com a mídia comunitária no Brasil. Anuário Internacional de Comunicação Lusófona. São Paulo: LUSOCOM, n.4, p.141-162, 2006.

RÊGO, Ana Regina. O Jornalismo Cultural na Revista O Cruzeiro. In: $9^{\circ}$ Encontro Nacional de História da Mídia, Minas Gerais, 2013.

ROMANCINI, Richard; LAGO, Cláudia. História do Jornalismo no Brasil. Florianópolis: Insular, 2007.

SOUSA, Jorge Pedro. Comunicação Regional e local na Europa Ocidental: os casos português e galego. Anuário UNESCO/UMESP de Comunicação, São Bernardo do Campo: UMESP, ano 7, n. 07, p. 83-127, 2004. 
TYLOR, Edward B. A ciência da cultura. In: Evolucionismo cultural: textos de Morgan, Tylor e Frazer. Trad. Maria Lúcia de Oliveira. $-2^{\mathrm{a}}$ ed. Rio de Janeiro: Jorge Zahar Ed., 2009. P. 67-99.

WILLIAMS, R. Cultura e Materialismo. São Paulo: Editora Unesp, 2011.

WHITE, L. A., DILLINGHAM, B. O conceito de cultura. Rio de Janeiro: Contraponto, 2009. (Originalmente publicado em 1975).

Enviado em 10/06/ 2018.

Publicado em 21/12/2018 